\title{
Clinical Profile and Outcome of Peripartum Cardiomyopathy among Teenager Patients at the University of the Philippines - Philippine General Hospital
}

\author{
Bee Jane T. Martinez, MD, Ma. Concepcion C. Sison, MD and Cecilienne S. Acosta, MD \\ Section of Pediatric Cardiology, Department of Pediatrics, Philippine General Hospital, University of the Philippines Manila
}

\begin{abstract}
Background. Peripartum cardiomyopathy (PPCM) is a rare form but life-threatening disease condition of the myocardium resulting in decreased ventricular contractility that occurs in a previously healthy woman during the peripartum period. Currently, in our country and probably worldwide there is an absence of epidemiologic data and description of the profile and outcome of PPCM patients less than 19 years old.
\end{abstract}

Objective. To determine the clinical profile and outcome of peripartum cardiomyopathy among teenagers (14-18 years old) at the University of the Philippines-Philippine General Hospital from 2004-2013

Methods. All patients aged 14-18 years old referred to Section of Pediatric Cardiology during a 10-year period from 2004-2013 who were diagnosed to have peripartum cardiomyopathy fulfilled the criteria set by National Heart, Lung and Blood Institute (NHLBI) were included in the study. We retrieved the medical records of the 25 patients diagnosed with peripartum cardiomyopathy from 2004-2013. The 2D echocardiogram was retrieved from the Pediatric Cardiology Section.

Results. There were 25 teenagers with a mean age of 17 years old diagnosed with PPCM in UP-PGH in 2004-2013. Twenty-one patients (84\%) had one sexual partner and two (8\%) patients had multiple sexual partners. Their common co-morbidity was preeclampsia. The most common symptoms were dyspnea, easy fatigability, and orthopnea. Most patients presented with NYHA functional class III-IV.

The majority had poor LV contractility (mean EF of $29 \%$ and a mean FS of $12.7 \%$ ). All had left ventricular enlargement with mean LVEDd of $5.3 \mathrm{~cm}$ and mean LVESd of $4.2 \mathrm{~cm}$. LV function improved in $72 \%$ of patients after six months. Four (16\%) patients died because of myocardial failure.

Conclusion. Peripartum cardiomyopathy is a rare form of cardiomyopathy but it can occur among teenagers age 14-18 years of age. Compared with the previous study our patients are younger, and with a low prevalence of multiple pregnancy and promiscuity. Similar to other studies, preeclampsia and premature labor necessitating the use of tocolytics with Terbutaline are common comorbidities.

Key Words: Peripartum Cardiomyopathy (PPCM), teen pregnancy, myocardial failure, heart failure

Poster presented at the $7^{\text {th }}$ World Congress of Pediatric Cardiology and Cardiac Surgery (WCPCCS), July 16-21, 2017, Barcelona, Spain; and at the University of the Philippines-Philippine General Hospital Fellow's Research Forum, November 2014, Philippines.

Corresponding author: Bee Jane T. Martinez, MD

Section of Pediatric Cardiology, Department of Pediatrics

Philippine General Hospital

University of the Philippines Manila

Taft Avenue, Manila 1000, Philippines

Email: pbjmartinez@gmail.com

\section{BACKGROUND}

Peripartum cardiomyopathy (PPCM) is a rare but lifethreatening disease condition of the myocardium resulting in decreased ventricular contractility that occurs in a previously healthy woman during the peripartum period. It is a rare cause of congestive heart failure that is associated with pregnancy. ${ }^{1,2}$ The precise mechanism of PPCM is not yet established but several plausible etiologic mechanisms 
have been suggested. Among them are viral infections, myocarditis, chimerism, apoptosis and inflammation, various hormones such as relaxin and prolaxtin, stressactivated cytokines, nutritional disorders, such as deficiencies in selenium and other micronutrients, and abnormal hemodynamic response..$^{3-9}$

Heart failure during pregnancy was already recognized as early as 1849 but PPCM was described as cardiomyopathy only in the 1930s. Postpartum cardiomyopathy is usually difficult to diagnose because the symptoms of heart failure mimics that of pregnancy; ${ }^{10-12}$ nevertheless, the following are the diagnostic criteria proposed by the National Heart, Lung and Blood Institute (NHLBI), with the National Institutes of Health $(\mathrm{NIH})^{13}$, (1) onset of heart failure signs and symptoms in the last month of pregnancy or within five months postpartum; (2) LV systolic dysfunction with ejection fraction (EF) measured less than or equal to $45 \%$ or $\mathrm{LV}$ end-diastolic dimension greater than or equal to $2.7 \mathrm{~cm} /$ $\mathrm{m}^{2}$; (3) no evidence of pre-existing heart disease prior to peripartum symptom onset; (4) no other identifiable causes of heart failure.

The National Hospital Discharge Survey (1990-2002) estimated that in the United States, PPCM complicates one in every 1,300 - 4,000 live births. ${ }^{14}$ There are various risk factors for PPCM reported worldwide such as multiparity, advanced maternal age, pregnancy-induced hypertension or preeclampsia, multiple gestations, obesity, chronic hypertension, and the prolonged use of tocolytics. ${ }^{15-20}$ There are reports that PPCM is 10 times more common in patients with African American descent. ${ }^{20}$ Demakis et al. found that African American women were 2.9 times more likely to have PPCM than were white women and seven times more likely than were Hispanic women., ${ }^{3,12}$ The morbidity and mortality rate is $5 \%$ to $32 \%$ in the United States and the outcome is highly variable. ${ }^{21}$

Demakis and colleagues suggest the following risk factors for PPCM: multiparity, advanced maternal age, multifetal pregnancy, preeclampsia, gestational hypertension and African American race. ${ }^{3}$

Beta-Adrenergic receptor agonist tocolysis has been reported to cause noncardiogenic pulmonary edema. Lampert et al. reported an association between chronic terbutaline therapy and cardiomyopathy in peripartum women. In their study, among 15 gravidas who had peripartum heart failure, four had received prolonged terbutaline tocolysis. Although those four patients had completely normalized ventricular function, only seven of the 11 others recovered. They suggested that gravidas receiving long-term betasympathomimetic tocolysis should undergo a close evaluation of cardiac function. ${ }^{18}$

Most patients who developed heart failure was exposed to different stress or injury. In the case of PPCM, pregnancy is believed to be the stress, but the mechanism is poorly understood. There are a lot of risk factors identified for the development of PPCM such as the age of more than 30 years old, hypertension, multiple pregnancies, exposure to alcohol and chemotherapy, genetic mutation, malnutrition and other medical condition such as diabetes mellitus, obesity, and chronic kidney disease which can worsen heart failure. ${ }^{22}$

Peripartum cardiomyopathy was also related to increased maternal age. The mean age of women with PPCM in the United States has ranged from 27 to 33 years with $>60 \%$ of patients reported in one study to be $>30$ years of age $\mathrm{e}^{23}$ and they also found out that multiple births (7\% to 14.5\%) have strong association with the development of postpartum cardiomyopathy compared with only $3 \%$ in the overall population. ${ }^{24}$ Multiparity was also considered as one of the risk factors, however, in the United States, they showed that $>50 \%$ of the patients developed postpartum cardiomyopathy on their first or second pregnancy. They concluded that multiparity and PPCM are not associated..$^{25}$

However, in our country and worldwide, data on prevalence and risk factors for the development of PPCM among teenagers are lacking. A study on PPCM in the Philippines was conducted by Samonte et.al but this was limited to patients ages 19 to 45 years old with a mean of 27 years old. ${ }^{26}$ This study aims to determine the clinical profile, echocardiographic findings and outcome of PPCM among teenagers age 14-18 years of age.

\section{METHODS}

This is a retrospective study conducted at the University of the Philippines- Philippine General Hospital. All patients aged 14-18 years old referred to Section of Pediatric Cardiology during a 10 year period from 2004-2013 who were diagnosed to have PPCM and fulfilled the 4-criteria for PPCM set by the National Heart, Lung and Blood Institute (NHLBI), with the National Institutes of Health (NIH) were included in this study. Patients with congenital heart disease or acquired heart disease (e.g. rheumatic fever, rheumatic heart disease, myocarditis, constrictive cardiomyopathy, and Kawasaki disease) were excluded from the study. Based on the census of the Section of Pediatric Cardiology of the UP-PGH, all medical records of 25 patients diagnosed with PPCM from 2004-2013 were retrieved. The $2 \mathrm{D}$ echocardiogram results were retrieved from the Pediatric Cardiology Section.

The following data were recorded particularly the following:

1. Demographic characteristics and clinical data

a. Age, parity, age of gestation, number of sex partners, type of birth, onset of symptoms, NYHA Functional class, mode of delivery, birth weight, Apgar score

b. Comorbid conditions such as preeclampsia, eclampsia, chronic hypertension, diabetes mellitus, history of smoking, drug use and alcohol intake, and use of tocolytics.

c. The signs and symptoms of the patients at the onset of diagnosis 
d. Medications for heart failure given to the patients and other management done to the patients

e. Maternal outcomes such as mortality, morbidity (persistence of heart failure symptoms after six months) and functional capacity on discharge were included

2. Echocardiographic parameters including ejection fraction (EF), fractional shortening (FS), Left ventricular end-diastolic diameter (LVEDD), Left ventricular end-systolic diameter (LVESD), presence of valvular regurgitation and chamber enlargement.

Descriptive statistics such as mean and standard deviation were computed for quantitative data and frequency and percentages were presented for categorical data.

\section{Ethical considerations}

This study was submitted to the PGH-EHRO for ethics review and approval. The principal investigator kept the records for the study. A study ID using numbers was assigned for each patient so as to maintain the patients' confidentiality. There was no conflict of interest.

\section{RESULTS}

Among 200 teenager deliveries in the UP-PH from 2004-2013, there were 25 patients diagnosed with PPCM who were included in the study. The mean age was 17 years old the youngest being 14 years old and the oldest was 18 years old.

Most patients had term deliveries at 37 weeks ( 37 weeks -39 weeks) and only two (8\%) had premature deliveries. Twenty-one (92\%) patients developed symptoms of heart failure after birth and 18 (72\%) presented with moderate to severe heart failure (NYHA Functional class III-IV). Among the 25 teenagers with PPCM, 21 (84\%) had spontaneous vaginal delivery, three $(12 \%)$ had a cesarian section and only one (4\%) patient had outlet forceps extraction. Almost all patients had one sexual partner and six patients (24\%) had multifetal delivery. (Table 1)

Preeclampsia is the most common co-morbid condition among patients with PPCM. Two (8\%) patients were noted to have eclampsia and one patient had diabetes mellitus. Only three (12\%) patients used tocolytics. None was a smoker or drug user. Two (8\%) patients were alcoholic beverage drinkers. (Table 2)

The most common presenting symptoms were dyspnea, (88\%) and easy fatigability, (88\%) and the most common physical findings were neck vein engorgement, (92\%) followed by bipedal edema, (28\%) and rales (20\%). (Tables 3 and 4)

With regard to echocardiographic findings, the majority of teenage patients showed global wall motion abnormalities. Most had poor contractility (EF 29\% and FS $12.7 \%$ ). The mean LVEDD was $5.3 \mathrm{~cm}$ and the mean
Table 1. Demographic and clinical profile of 25 patients with peripartum cardiomyopathy

\begin{tabular}{|c|c|}
\hline Age (years), mean (SD) & 17 years old \pm 1.3 ( $14-18$ years old $)$ \\
\hline \multicolumn{2}{|l|}{ Parity } \\
\hline 1 & 21 (84\%) \\
\hline 2 & $2(8 \%)$ \\
\hline 3 & $2(8 \%)$ \\
\hline 4 & 0 \\
\hline Age of Gestation, mean (SD) & $37 w k s \pm 0.8$ (35 wks - 39 wks) \\
\hline $\begin{array}{l}\text { Number of Sex Partners, } \\
\text { mean (SD) }\end{array}$ & $\begin{array}{c}1 \text { sexual partner (84\%) } \\
2 \text { sexual parters ( } 8 \%) \\
3 \text { or more sexual partners (8\%) }\end{array}$ \\
\hline \multicolumn{2}{|l|}{ Type of Birth, n (\%) } \\
\hline Single & $19(76 \%)$ \\
\hline Twin & $6(24 \%)$ \\
\hline Triplet & 0 \\
\hline \multicolumn{2}{|l|}{ Onset of Symptoms, n (\%) } \\
\hline After delivery & $23(92 \%)$ \\
\hline Before delivery & $2(8 \%)$ \\
\hline \multicolumn{2}{|l|}{ NYHA Functional class, n (\%) } \\
\hline I & $1(4 \%)$ \\
\hline II & 0 \\
\hline III & 18 (72\%) \\
\hline IV & $6(24 \%)$ \\
\hline \multicolumn{2}{|l|}{ Mode of Delivery, $\mathrm{n}(\%)$} \\
\hline SVD & 21 (84\%) \\
\hline CS & $3(12 \%)$ \\
\hline OFE & $1(4 \%)$ \\
\hline \multicolumn{2}{|l|}{ Birth Weight, n (\%) } \\
\hline AGA & $24(96 \%)$ \\
\hline SGA & $1(4 \%)$ \\
\hline LGA & 0 \\
\hline
\end{tabular}

SVD - Spontaneous Vaginal delivery, CS - Cesarian Section, OFE Outlet forceps extraction, AGA - Appropriate for gestational age, SGA Small for gestational age, LGA - Large for gestational age

Table 2. Co morbid conditions of 25 patients with peripartum cardiomyopathy

\section{Co morbid conditions}

Patients (n/\%)

Preeclampsia, $\mathrm{n}(\%)$

$10(40 \%)$

Eclampsia, $\mathrm{n}(\%)$

Chronic Hypertension, $\mathrm{n}(\%)$

Diabetes Mellitus, $\mathrm{n}(\%)$

History of Smoking, $\mathrm{n}(\%)$

Drug Use, $\mathrm{n}(\%)$

Alcohol Intake, $\mathrm{n}(\%)$

$2(8 \%)$

0

$1(4 \%)$

0

0

Use of Tocolytics, $n$ (\%)

$2(8 \%)$

$3(12 \%)$

Table 3. Symptoms of 25 patients diagnosed with peripartum cardiomyopathy

\section{Symptoms}

Patients (n/\%)

Cough, $\mathrm{n}(\%)$

$4(16 \%)$

Difficulty of breathing, $\mathrm{n}(\%)$

$22(88 \%)$

Easy fatigability, $\mathrm{n}(\%)$

Orthopnea, n (\%)

Chest pain, $n(\%)$

Fatigue, $\mathrm{n}(\%)$

Palpitations, $n(\%)$

$22(88 \%)$

$7(28 \%)$

$1(4 \%)$

0

$4(16 \%)$

Paroxysmal nocturnal dyspnea, $\mathrm{n}(\%)$

Abdominal pain, $\mathrm{n}(\%)$
$3(12 \%)$

0 
Table 4. Physical examination of 25 patients with peripartum cardiomyopathy

\begin{tabular}{lc} 
Physical examination & Patients (n/\%) \\
Neck vein engorgement, $\mathrm{n}(\%)$ & $23(92 \%)$ \\
Rales, $\mathrm{n}(\%)$ & $5(20 \%)$ \\
Murmur, n (\%) & 0 \\
Gallop Rhythm, n (\%) & $4(16 \%)$ \\
Hepatomegaly, n (\%) & $2(8 \%)$ \\
Bipedal Edema, n (\%) & $7(28 \%$ \\
\hline
\end{tabular}

Table 5. Echocardiographic parameters of 25 patients with peripartum cardiomyopathy

\begin{tabular}{lc} 
Echocardiographic parameters & Patients (n/\%) \\
Ejection fraction, (\%) & $29 \% \pm 11.9(4-50 \%)$ \\
Fractional Shortening, (\%) & $12.7 \% \pm 5.5(2-20 \%)$ \\
LVEDD (cm) & $5.3 \mathrm{~cm} \pm 12.8(3.5-7.9 \mathrm{~cm})$ \\
LVESD, mean (SD) & $4.7 \mathrm{~cm} \pm 7.2(3.6-6.4 \mathrm{~cm})$ \\
Valvular Regurgitation, $\mathrm{n}(\%)$ & \\
Mitral valve & $23(92 \%)$ \\
Tricuspid valve & $15(60 \%)$ \\
$\quad$ Aortic valve & $9(36 \%)$ \\
Chamber Enlargement, $\mathrm{n}(\%)$ & $25(100 \%)$ \\
\hline
\end{tabular}

LVEDD - left ventricular end diastolic dimension, LVESD - left ventricular end systolic dimension

Table 6. Managements and medications for heart failure given to the 25 patients with peripartum cardiomyopathy

Managements and Medications Patients (n/\%)

Diuretics, $\mathrm{n}(\%)$ $25(100 \%)$

Digoxin, $\mathrm{n}(\%)$

$25(100 \%)$

Beta Blocker, $\mathrm{n}(\%)$

$6(24 \%)$

Ace inhibitors, $\mathrm{n}(\%)$

$25(100 \%)$

Calcium Channel Blockers, $\mathrm{n}$ (\%)

Nitrates, n (\%)

Angiotensin Receptor Blocker, $\mathrm{n}(\%)$

Oxygen, $\mathrm{n}$ (\%)

Water and salt restriction, $\mathrm{n}(\%)$

Complete bed rest, $\mathrm{n}$ (\%)

0

0

0

$25(100 \%)$

$25(100 \%)$

$25(100 \%)$

${ }^{*}$ Some patients may have more than five medications

Table 7. Outcomes of 25 patients diagnosed to have peripartum cardiomyopathy

\section{Outcomes}

Patients (n/\%)

Discharge, $\mathrm{n}(\%)$

$18(72 \%)$

Mortality, $\mathrm{n}(\%)$

$4(16 \%)$

Lost to follow up, $\mathrm{n}(\%)$

$3(12 \%$

LVESd was $4.7 \mathrm{~cm}$. Twenty three (92\%) patients had valvular regurgitation, the mitral valve being the most frequently involved. All patients had chamber enlargement. (Table 5)

All patients were given diuretics, digoxin and ace inhibitor (captopril and enalapril). Only 6 (24\%) patients use beta-blocker (carvedilol) and none of the patients were given calcium channel blocker, nitrates or angiotensin receptor blocker. The majority was given oxygen and placed in bed rest and water and salt were restricted in all patients. (Table 6)

Eighteen (72\%) patients were discharged with improved left ventricular contractility, four (16\%) patients died but none of those patients used tocolytics and three
(12\%) patients were lost to follow up. (Table 7) Among those with improved contractility, 18 had normalization of ejection fraction.

\section{DISCUSSION}

\section{Prevalence and Comorbidities}

The incidence of PPCM is geographically variable, ranging from 1 in 15000 deliveries in the United States, and a high incidence in Nigeria of 1 in 100 deliveries. ${ }^{27-29}$ There were 25 teenagers with PPCM among 200 teenage deliveries in a tertiary government institution in the Philippines. Its incidence in the country nevertheless remains to be seen, and should particularly be monitored. The incidence of PPCM is high in developing countries. ${ }^{26}$ The high variability of PPCM incidence in different countries is probably because of differences in cultural practices and standards of perinatal care and maybe the biggest contributors are the environmental and genetic factors. ${ }^{30}$

International studies showed that there are various risk factors for the development of PPMC such as older age, multiple gestations, multiple fetuses, low socioeconomic status, history of preeclampsia, black, age, malnutrition and use of tocolytics. $3,20,23,25$

In our study, we showed that PPCM can occur in teenaged patients ranging from 15-18 years old with a mean of 17 years old and most of them are primigravid. This supports the hypothesis that PPCM can occur at any age. Laghari et $\mathrm{al}^{31}$ showed that among 45 patients with PPCM, 25 (55.5\%) were primigravida, eight (17.7\%) were gravida 2, and the remaining $12(26.6 \%)$ were multigravidas. Thirteen (28.8\%) patients were more than 30 years of age. They also stated that PPCM generally occurs in women over the age of 30 years but it can happen at any age. They found out that it is observed in all races and multiparity is a risk factor. The most common age groups of patients with PPCM are ranging from 19-40 years old according to international studies. Peripartum cardiomyopathy is more likely to occur in the older and multiparous female but a study done by Desai et al. showed that although multiparous women who are older than 30 years of age are recognized to be at increased risk for PPCM, it is important to note that $18 \%$ to $20 \%$ of the cases may be young primigravid patients. ${ }^{32,33}$

Poor socioeconomic status is identified as one of the causes of PPCM. Most of our patients are out of school youth and unemployed. Poverty as a risk factor for the development of PPCM is probably because of the increased incidence of communicable diseases among the low socioeconomic population and poor sanitation and poor hygiene. ${ }^{22}$ They also experience a high incidence of viral diseases such as parvovirus B19, human herpes virus 6, Epstein-Barr virus and cytomegalovirus ${ }^{34}$ that may cause viral myocarditis. Viral myocarditis is also considered as one of the predisposing factors for the development of PPCM probably because 
Peripartum Cardiomyopathy among Teenagers

of a pathologic immune response such as interstitial and perivascular inflammation that is inappropriately directed against native cardiac tissue proteins that leads to the cardiomyocyte necrosis and eventually leads to ventricular dysfunction. ${ }^{34}$ The reported incidence of myocarditis in PPCM ranges from $29 \%$ to $100 \%{ }^{35}$ and $31 \%$ of the cases are caused by viruses. ${ }^{36}$

We showed that most of our patients with PPCM had single gestation and one sexual partner. This is most likely due to a recent onset of puberty and limited exposure to other sexual partners based on age alone. Twenty-one patients (84\%) had one sexual partner and two (8\%) patients had multiple sexual partners. Nineteen (76\%) patients had single gestation and six (24\%) patients had twin pregnancies in contrast to the adult population which had more nonsingleton pregnancies 23 that were different compared to the adult population. The exact relationship between the number of pregnancies, number of sexual partners, and PPCM is not yet fully understood. The study conducted by Murali et $\mathrm{al}^{37}$ showed that twin pregnancies are observed in $13 \%$ of patients with PPCM compared with $1 \%$ of healthy women. In a review, they showed that there is a high prevalence of multiple pregnancies among patients who developed PPCM compared with the general population and most of them have multiple sexual partners. $3,23,25$

The exact etiology of PPCM is still unknown and may be multifactorial. The most common comorbidity identified in our study for the development of PPCM is preeclampsia. The pathophysiology of preeclampsia causing PPCM is poorly understood but it was hypothesized that the hemodynamic stress caused by preeclampsia may contribute to the development of PPCM. ${ }^{33}$ In our study, ten (40\%) out of 25 patients had preeclampsia and two patients (8\%) were diagnosed with eclampsia which is comparable to other studies. Preeclampsia and multiple gestations were shown to be associated with PPCM. In a systematic review done by Bello et al. ${ }^{23}$ there was a markedly high prevalence of hypertension 37\% [95\% CI: $29 \%$ to $45 \%$ ]) and multiple pregnancy (9\% [95\% CI: $7 \%$ to $11 \%]$ ) among patient who developed PPCM compared with the general population $(5 \% \mathrm{p}<0.001) .{ }^{23}$ There is a higher incidence of PPCM (43\%) among patients with gestational hypertension based on the report done by Elkayam et al. ${ }^{38}$ compared with $8 \%$ to $10 \%$ incidence with overall pregnant population. ${ }^{2}$. These findings showed that the pathogenesis of preeclampsia and PPCM were more likely related. ${ }^{39}$

Among our patients with PPCM, three (12\%) patients used tocolytics and two (8\%) patients were alcohol beverage drinkers. Murali et al. ${ }^{37}$ showed that there is a risk association between PPCM and tocolytic therapy. The tocolytic agent is a beta sympathomimetic found to cause pulmonary edema among pregnant women linking it for the development of PPCM. ${ }^{33}$

Among our subjects, the most common symptoms were dyspnea, easy fatigability and orthopnea. Six (24\%) and $18(72 \%)$ patients had NYHA functional class III and IV, respectively on admission. The symptoms started a few months postpartum in 23 (92\%) patients; two (8\%) of our cases occurred prepartum which was congruent to other studies. All our patients were given diuretics, digoxin, ace inhibitor and oxygen as a treatment for heart failure consistent with the standard treatment for symptomatic cardiomyopathy. Even though we have patients with preeclampsia no one was given calcium channel blocker, nitrates, and angiotensin receptor blocker probably because their hypertension was already controlled by other medications such as diuretics and beta-blocker. PPCM usually occurs in the first four months postpartum and signs and symptoms lasted for six months and prenatally occur in less than 10\% of the cases. ${ }^{38}$ The most common symptoms are orthopnea, cough, hemoptysis and paroxysmal nocturnal dyspnea.

\section{Echocardiographic Findings}

The echocardiogram is the most common diagnostic tool for PPCM..$^{20}$ The global reduction in contractility and $\mathrm{LV}$ enlargement without hypertrophy is the most common echocardiographic findings. ${ }^{20,29}$ All of our patients had a global reduction in contractility specifically left ventricular dysfunction and the mean ejection fraction was 29\% (range 4-50\%) and fractional shortening of $12.7 \%$ (range 2-20\%). The mean LVEDD was $5.3 \mathrm{~cm}$ and the mean LVESD was $4.7 \mathrm{~cm}$. Anirban et $\mathrm{al}^{30}$ showed other echocardiographic findings including left atrial enlargement, mitral and tricuspid regurgitation, pericardial effusion and mural thrombus. ${ }^{34}$ In our study, ten (40\%) patients had left atrial enlargement, twenty-three (92\%) patients had valvular regurgitation all of whom had mitral regurgitation. Fifteen patients (60\%) had associated tricuspid regurgitation while nine patients (36\%) also had aortic regurgitation Six (24\%) patients had pericardial effusion. None of the patients developed mural thrombus. All patients had associated left ventricular enlargement and right ventricular hypertrophy.

\section{Maternal outcome and fetal outcome}

If the maternal and fetal conditions are stable, early delivery in patients with PPCM is not required according to the 2010 European society of cardiology working group statement. ${ }^{40}$ It was found out that fetal outcome was not adversely affected by increasing age and multiparity. ${ }^{40,41}$ In our study, most of the deliveries were term; with two (8\%) preterm and both mothers had preeclampsia. The average gestation was 37 weeks. All newborns were born with an Apgar score of 9 in 1 minute and 9 in 5 minutes. No newborn developed complications and died of any disease. With these, we can say that the fetal outcome is not affected by PPCM probably because the symptoms of heart failure were noted after delivery. For the past five years, there was a significant improvement in medical therapy for heart failure thus a decrease in the morbidity and mortality rate of PPCM. According to Elkayam et al., ${ }^{38}$ the maternal 
morbidity was $9 \%$ with a $14 \%$ rate of death or cardiac transplantation. ${ }^{38}$ Based on Murali et al. ${ }^{37}$ more than $50 \%$ of women who developed PPCM were noted to have improved left ventricular function and normalizing after six months. ${ }^{37}$ The initial LVESD of $5.5 \mathrm{~cm}$ or less ${ }^{42}$ and an LVEF greater than $27 \% \%^{42}$ or $30 \%{ }^{38}$ are associated with the normalization of left ventricular function after six months. In our study, $72 \%$ of PPCM patients had improved LVEF from 35-50\% to $40 \%-55 \%$ and mitral regurgitation also improved in $72 \%$ of the patients. Four (16\%) mothers died of myocardial failure and three (12\%) patients were lost to follow up due to unknown reasons.

\section{CONCLUSION}

There were 25 teenagers in 200 teenage deliveries with a mean age of 17 years old diagnosed with PPCM in UPPGH in 2004-2013. The most common co-morbidity is preeclampsia. The most common symptoms were difficulty of breathing, easy fatigability, and orthopnea. Most patients presented with NYHA functional class III-IV. Majority had poor LV contractility (mean EF of $29 \%$ and mean FS of $12.7 \%)$. All had left ventricular enlargement with mean LVEDd of $5.3 \mathrm{~cm}$ and mean LVESd of $4.2 \mathrm{~cm}$. LV function improved in $72 \%$ of patients after six months. Four (16\%) patients died because of myocardial failure.

\section{Recommendations}

We recommend the following subsequent studies based on the limitation and results of our study:

1. Determination of whether the above comorbidities are risk factors for the development of PPCM

2. Long term follow up of the discharged patients to monitor the subsequent course

3. Incidence or recurrence of PPCM in their subsequent pregnancies.

\section{Statement of Authorship}

The main author collected and analyzed the data. The co-authors reviewed and checked the paper. All authors approved the final version submitted.

\section{Author Disclosure}

All authors declared no conflicts of interest.

\section{Funding Source}

This paper was funded by the main author.

\section{REFERENCES}

1. Hibbard JU, Lindheimer M, Lang RM. A modified definition for peripartum cardiomyopathy and prognosis based on echocardiography. Obstet Gynecol. 1999 Aug; 94(2):311-6. doi: 10.1016/s00297844(99)00293-8.

2. Maron BJ, Towbin JA, Thiene G, Antzelevitch C, Corrado D, Arnett D, et al. Contemporary definitions and classification of the cardiomyopathies. An American Heart Association scientific statement from the Council on Clinical Cardiology, Heart Failure and Transplantation Committee; Quality of Care and Outcomes Research and Functional Genomics and Translational Biology Interdisciplinary Working Groups; and Council on Epidemiology and Prevention. Circulation 2006 Apr; 113(14):1807-16. doi: 10.1161/ CIRCULATIONAHA.106.174287.

3. Demakis JG, Rahimtoola SH, Sutton GC, Meadows WR, Szanto PB, Tobin JR, et al. Natural course of peripartum cardiomyopathy. Circulation. 1971 Dec; 44(6):1053-61. doi: 10.1161/01.cir.44.6.1053.

4. Tidswell M. Peripartum cardiomyopathy. Crit Care Clin. 2004 Oct; 20(4):777-88. doi: 10.1016/j.ccc.2004.05.007.

5. Fett JD, Christie LG, Carraway RD, Ansari AA, Sundstrom JB, Murphy JG. Unrecognized peripartum cardiomyopathy in Haitian women. Int J Gynaecol Obstet. 2005 Aug; 90(2):161-6. doi: 10.1016/ j.ijgo.2005.05.004.

6. Mielniczuk LM, Williams K, Davis DR, Tang ASL, Lemery R, Green MS, et al. Frequency of peripartum cardiomyopathy. Am J Cardiol. 2006 Jun; 97(12):1765-8. doi: 10.1016/j.amjcard.2006.01.039.

7. Sliwa K, Skudicky D, Bergemann A, Candy G, Puren A, Sareli P. Peripartum cardiomyopathy: analysis of clinical outcome, left ventricular function, plasma levels of cytokines and Fas/APO-1. J Am Coll Cardiol. 2000 Mar; 35(3):701-5. doi: 10.1016/s07351097(99)00624-5.

8. McKenna W. Diseases of the myocardium and endocardium. In: Goldman L, Schafer AI, eds. Cecil Medicine. 24th ed. Philadelphia, PA: Saunders Elsevier; 2011.

9. Warnes CA. Pregnancy and heart disease. In: Bonow RO, MannDL, Zipes DP, Libby P, eds. Braunwald's Heart Disease: A Textbook of Cardiovascular Medicine. 9th ed. Philadelphia, Pa: Saunders Elsevier; 2011.

10. Bultmann BD, Klingel K, Nabauer M, Wallwiener D, Kandolf R. High prevalence of viral genomes and inflammation in peripartum cardiomyopathy. Am J Obstet Gynecol. 2005 Aug; 193(2):363-5. doi: 10.1016/j.ajog.2005.01.022.

11. Kühl U, Pauschinger M, Seeberg B, Lassner D, Noutsias M, Poller $\mathrm{W}$, et al. Viral persistence in the myocardium is associated with progressive cardiac dysfunction. Circulation 2005 Sep; 112(13): 1965-70. doi: 10.1161/CIRCULATIONAHA.105.548156.

12. Elkayam U, Akhter MW, Singh H, Khan S, Bitar F, Hameed A, et al. Pregnancy associated cardiomyopathy. Clinical characteristics and a comparison between early and late presentations. Circulation. 2005 Apr; 111(16):2050-5. doi: 10.1161/01.CIR.0000162478. 36652.7E.

13. Borghi C, Esposti DD, Immordino V, Cassani A, Boschi S, Bovicelli $\mathrm{L}$, et al. Relationship of systemic hemodynamics, left ventricular structure and function, and plasma natriuretic peptide concentrations during pregnancy complicated by preeclampsia. Am J Obstet Gynecol. 2000 Jul; 183(1):140 -7. doi: 10.1067/mob.2000.105684.

14. Hogle KL, Hutton EK, McBrien KA, Barrett JF, Hannah ME. Cesarean delivery for twins: a systematic review and meta-analysis. Am J Obstet Gynecol. 2003 Jan; 188(1):220 -7. doi: 10.1067/mob.2003.64.

15. Silversides CK, Colman JM, Sermer M, Siu SC. Cardiac risk in pregnant women with rheumatic mitral stenosis. Am J Cardiol. 2003 Jun; 91(11):1382-5. doi: 10.1016/s0002-9149(03)00339-4.

16. Alvarez Navascues R, Marin R, Testa A, Paneda F, Alvarez Grande J. Preeclampsia and peripartum cardiomyopathy: infrequent association. Nefrologia. 2001; 21:84-7.

17. Ansari AA, Neckelmann N, Wang YC, Gravanis MB, Sell KW, Herskowitz A. Immunologic dialogue between cardiac myocytes, endothelial cells, and mononuclear cells. Clin Immunol Immunopathol.1993; 68:208-14.

18. Lampert MB, Hibbard J, Weinert L, Briller J, Lindheimer M, Lang RM. Peripartum heart failure associated with prolonged tocolytic therapy. Am J Obstet Gynecol. 1993 Feb; 168(2):493-5. doi: 10.1016/ 0002-9378(93)90479-3.

19. Zhang J, Meikle S, Grainger DA, Trumble A. Multifetal pregnancy in older women and perinatal outcomes. Fertil Steril. 2002 Sep; 78(3):562-8. doi: 10.1016/s0015-0282(02)03272-7. 
20. Selle T, Renger I, Labidi S, Bultmann I, Hilfiker-Kleiner D. Reviewing peripartum cardiomyopathy: current state of knowledge. Future Cardiol. 2009 Mar; 5(2):175-89. doi: 10.2217/14796678.5.2.175.

21. Pearson GD, Veille JC, Rahimtoola S, Hsia J, Oakley CM, Hosenpud JD, et al. Peripartum cardiomyopathy: National Heart, Lung, and Blood Institute and Office of Rare Diseases (National Institutes of Health) workshop recommendations and review. JAMA. 2000 Mar; 283(9): 1183-8.

22. Givertz MM. Cardiology patient page: peripartum cardiomyopathy. Circulation. 2013 May; 127(20): e622-6. doi: 10.1161/ CIRCULATIONAHA.113.001851.

23. Bello N, Hurtado Rendon IS, Arany Z. The relationship between pre-eclampsia and peripartum cardiomyopathy. a systematic review and meta-analysis. J Am Coll Cardiol. 2013 Oct; 62(18):1715-23. doi: 10.1016/j.jacc.2013.08.717.

24. Chapa JB, Heiberger HB, Weinert L, DeCara J, Lang RM, Hibbard JU. Prognostic value of echocardiography in peripartum cardiomyopathy. Obstet Gynecol. 2005 Jun; 105(6):1303-8. doi: 10.1097/01.AOG.0000161382.30233.ba.

25. Amos AM, Jaber WA, Russell SD. Improved outcomes in peripartum cardiomyopathy with contemporary. Am Heart J. 2006 Sep; 152(3):509-13. doi: 10.1016/j.ahj.2006.02.008.

26. Samonte VI, Ngaloob QG, Mata GDB, Aherrera JAM, Reyes E, Punzalan FER. Clinical and echocardiographic profile and outcomes of peripartum cardiomyopathy: the Philippine General Hospital experience. Heart Asia. 2013 Nov; 5(1):245-9. doi: 10.1136/ heartasia-2013-010356.

27. Sanderson JE, Adesanya CO, Anjorin FI, Parry EH. Postpartum cardiac failure--heart failure due to volume overload? Am Heart J. 1979 May; 97(5):613-21.

28. Fett JD, Christie LG, Carraway RD, Murphy JG. Five-year prospective study of the incidence and prognosis of peripartum cardiomyopathy at a single institution. Mayo Clin Proc. 2005 Dec; 80(12):1602-6. doi: 10.4065/80.12.1602.

29. Sliwa K, Damasceno A, Mayosi BM. Epidemiology and etiology of cardiomyopathy in Africa. Circulation. 2005 Dec; 112(23):3577-83. doi: 10.1161/CIRCULATIONAHA.105.542894.

30. Bhattacharyya A, Basra SS, Sen P, Kar B. Peripartum cardiomyopathy: a review. Tex Heart Inst J. 2012; 39 (1):8-16

31. Laghari AH, Khan AH, Kazmi KA. Peripartum cardiomyopathy: ten year experience at a tertiary care hospital in Pakistan. BMC Res Notes. 2013 Dec; 6:495. doi: 10.1186/1756-0500-6-495.
32. Desai D, Moodley J, Naidoo D. Peripartum cardiomyopathy: experiences at King Edward VIII Hospital, Durban, South Africa and a review of literature. Trop Doct. 1995 Jul; 25(3):118-23. doi: 10.1177/004947559502500310.

33. Forster OA, Essop MR, Zhanje F, Candy G, Libhaber E, Phooko B, et al. Peripartum cardiomyopathy: clinical profile in 100 prospective patients studied at a single centre. Circulation. 2003; 108:663. Abstract.

34. Melvin KR, Richardson PJ, Olsen EG, Daly K, Jackson G. Peripartum cardiomyopathy due to myocarditis. N Engl J Med.1982 Sep; 307(12):731-4. doi: 10.1056/NEJM198209163071207.

35. Bhakta P, Biswas BK, Banerjee B. Peripartum cardiomyopathy: review of the literature. Yonsei Med J. 2007 Oct; 48(5):731-47. doi: 10.3349/ ymj.2007.48.5.731

36. Bultmann BD, Klingel K, Nabauer M, Wallwiener D, Kandolf R. High prevalence of viral genomes and inflammation in peripartum cardiomyopathy. Am J Obstet Gynecol. 2005 Aug; 193(2):363-5. doi: 10.1016/j.ajog.2005.01.022.

37. Murali S, Baldiserri MR. Peripartum cardiomyopathy. Crit Care Med. 2005 Oct; 33(10 Suppl):S340-6. doi: 10.1097/01.ccm. 0000183500.47273.8e.

38. Elkayam U. Clinical characteristics of peripartum cardiomyopathy in the United States: diagnosis, prognosis, and management. J Am Coll Cardiol. 2011 Aug; 58(7):659-70. doi: 10.1016/j.jacc.2011.03.047.

39. Chari RS, Frangieh AY, Sibai BM. Hypertension during pregnancy: diagnosis, pathophysiology and management. In: Elkayam U, Gleicher N, eds. Cardiac Problems in Pregnancy. 3rd ed. New York, NY: Wiley Liss Inc.; 1998. pp. 257-273.

40. Sliwa K, Hilfiker-Kleiner D, Petrie MC, Mebazaa A, Pieske B, Buchmann E, et al. Current state of knowledge on aetiology, diagnosis, management, and therapy of peripartum cardiomyopathy: a position statement from the Heart Failure Association of the European Society of Cardiology Working Group on peripartum cardio myopathy. Eur J Heart Fail. 2010 Aug; 12(8):767-78. doi: 10.1093/ eurjhf/hfq120.

41. Lampert MB, Lang RM, Peripartum cardiomyopathy. Am Heart J. 1995 Oct; 130(4):860-70. doi: 10.1016/0002-8703(95)90089-6.

42. Duran N, Gunes H, Duran I, Biteker M, Ozkan M. Predictors of prognosis in patients with peripartum cardiomyopathy. Int J Gynaecol Obstet. 2008 May; 101(2):137-40. doi: 10.1016/j.ijgo. 2007.11.007. 